\title{
Erratum zu: Methodische Unterstützung für die Gestaltung analysebasierter Dienstleistungen
}

\author{
Florian Kiefer • Katrin Joussen · Fabian Hunke
}

Angenommen: 19. Mai 2021 / Online publiziert: 25. Juni 2021

(C) Der/die Autor(en) 2021

\section{Erratum zu:}

\section{HMD 2020}

https://doi.org/10.1365/s40702-020-00642-7

Der Artikel Methodische Unterstützung für die Gestaltung analysebasierter Dienstleistungen von Florian Kiefer, Katrin Joussen und Fabian Hunke wurde ursprünglich Online First ohne „Open Access“ auf der Internetplattform des Verlags publiziert. Nach der Veröffentlichung in Band 57 Heft 4 pp. 684-696 hatten sich die Autoren für eine „Open Access“-Veröffentlichung entschieden. Das Urheberrecht des Artikels wurde deshalb in (C) Die Autoren 2020 geändert.

Funding Open access funding enabled and organized by Projekt DEAL.

Open Access Dieser Artikel wird unter der Creative Commons Namensnennung 4.0 International Lizenz veröffentlicht, welche die Nutzung, Vervielfältigung, Bearbeitung, Verbreitung und Wiedergabe in jeglichem Medium und Format erlaubt, sofern Sie den/die ursprünglichen Autor(en) und die Quelle ordnungsgemäß nennen, einen Link zur Creative Commons Lizenz beifügen und angeben, ob Änderungen vorgenommen wurden.

Die in diesem Artikel enthaltenen Bilder und sonstiges Drittmaterial unterliegen ebenfalls der genannten Creative Commons Lizenz, sofern sich aus der Abbildungslegende nichts anderes ergibt. Sofern das betref-

Die Online-Version des Originalartikels ist unter https://doi.org/10.1365/s40702-020-00642-7 zu finden.

Florian Kiefer

EnBW Energie Baden-Württemberg AG, Durlacher Allee 93, 76131 Karlsruhe, Deutschland

Katrin Joussen · Fabian Hunke $(\bowtie)$

Karlsruhe Service Research Institute, Karlsruher Institut für Technologie (KIT),

Kaiserstr. 89, 76133 Karlsruhe, Deutschland

E-Mail: fabian.hunke@kit.edu 
fende Material nicht unter der genannten Creative Commons Lizenz steht und die betreffende Handlung nicht nach gesetzlichen Vorschriften erlaubt ist, ist für die oben aufgeführten Weiterverwendungen des Materials die Einwilligung des jeweiligen Rechteinhabers einzuholen.

Weitere Details zur Lizenz entnehmen Sie bitte der Lizenzinformation auf http://creativecommons.org/ licenses/by/4.0/deed.de. 